кандидат социологических наук, доцент кафедры государственного и муниципального управления

Северо-Кавказского федерального университета

\section{РЕПРОДУКЦИЯ КУЛЬТУРНОЙ СИСТЕМЫ КАК СОЦИАЛЬНАЯ ФУНКЦИЯ ВЫСШЕГО ОБРАЗОВАНИЯ}

Аннотация:

В статье рассматривается проблема изучения, объяснения и интерпретации социальных функций высшего образования, среди которых репродукция культурной системы признается центральной. Проблематика данной социальной функции образования определяется с позиции структурно-функционального анализа, в рамках которого образовательная система трактуется как исходная установка социокультурного подхода. В работе демонстрируются недостатки «упрощения» структурно-функционального подхода применительно к высшей школе. Работа основана на использовании обще- $и$ частнонаучных методик, включая упомянутый структурно-функциональный анализ, а также методов, характерных для исследования социальных институтов и процессов. Ключевые выводы состоят в том, что квалификационная функция высшего образования выражается в репродукции культурной системы, без осуществления и усвоения которой невозможно обеспечить участие современного человека в общественной жизни.

Ключевые слова:

образование, высшее образование, образовательная система, социальные функции, репродукция культуры, структурно-функциональный анализ, квалификация.
PhD in Social Science, Associate Professor, Department of State and Municipal Administration, North Caucasus Federal University

\section{THE REPRODUCTION OF THE CULTURAL SYSTEM AS A SOCIAL FUNCTION OF HIGHER EDUCATION}

Summary:

The paper deals with the problems of studying, explaining and interpreting the social functions of higher education. In this context, the reproduction of the cultural system is the key issue. The problems of this social function of education are determined from the standpoint of the structural and functional analysis which considers the education system as the initial principle of social and cultural approach. The study demonstrates the shortcomings of the simplified structural and functional analysis of higher education. The research is based on general and specific scientific research methods, including the above-mentioned structural and functional approach, and the techniques which are typical for the study of social institutions and processes. The key findings of the research demonstrate that the qualification function of higher education is justified as a reproduction of the cultural system that is to be implemented and assimilated in order to ensure the participation of modern people in public life.

Keywords:

education, higher education, education system, social functions, cultural reproduction, structural and functional analysis, qualification.

Образовательная система любого социума в современном мире является важнейшей гарантией устойчивости его развития. «Образовательная система, - пишет один из ведущих европейских исследователей проблематики социологии образования Г. Фенд, - это система, в которой процессы социализации организованы коллективно. Она формирует членов общества, способных к поступкам и общению, и благодаря этому способствует стабильности современных обществ» [1, S. 35]. Она тесно переплетена с другими структурами общества: политической, экономической, духовнонравственной, правовой и др. При этом значение образования проявляется не только в том, что оно выполняет некую посредническую функцию между, например, политической и экономической структурами. Его роль существенно шире: оно выступает мощнейшим фрактором прогресса общества и его основных институтов. Дефекты и неэффективные компоненты образовательного механизма причиняют гражданам больший вред, чем многие другие непродуктивные социальные инструменты. Причем этот вред проявляется не сразу, он аккумулируется и, наконец, разрушает социальные процессы, ведет к длительной деградации общественных структур, девальвации культурной среды, резкому снижению уровня профессиональных компетенций, что в свою очередь оказывает деструктивное влияние на все остальные структурные элементы государства.

По мере развития общество начинает предъявлять к образовательной системе все более высокие и строгие требования. Интенсификация социальных процессов требует от нее своевременной и адекватной реакции. Однако при этом образовательная система не может играть роль пожарной команды, которую каждый раз вызывают для разрешения критических ситуаций. Очевидным и необходимым свойством эффеективного образования является разумная индифферентность по отношению к стихийности социальных процессов и вызовов. Образовательный механизм должен перманентно осуществлять ряд важных социальных фрункций, от продуктивности выполнения которых в конечном счете зависит стабильность социума, а также разных инструментов и форм социализации. 
Высшее образование как часть многоуровневой образовательной структуры общества в современном мире подвергается интенсивным трансформациям и воздействиям, обусловленным как внешними причинами, так и внутренними. В частности, интеграция российской высшей школы в единые модели общеевропейского образования способствовала тому, что в нашей стране была введена двухуровневая система подготовки специалистов. Этот фактор имел внешний характер, он не был вызван внутренними социальными требованиями. Несмотря на то что эта схема реализуется в России уже достаточно долгое время, ее нельзя назвать органичной (а не только формальной) частью национальной образовательной системы. В данном случае последняя трактуется не как нормативная часть формализованной институциональной среды для просвещения и образования, а как фрактически функционирующая система структур и институциональных компонентов, обеспечивающих репродукцию культурной системы. В связи с этим квалификация рассматривается не как формальная, технократическая модель воспроизводства знаний и навыков, а как система, обеспечивающая знания и навыки, необходимые для уверенного и эффективного (в личностном, групповом и коллективном планах) участия человека в общественной жизни, социокультурном общении и взаимодействии.

Н.3. Кобжицкая при исследовании социализации как функции института образования справедливо отмечает, что «проблема содержательных сторон процесса социализации в структуре института образования» тесно связана с вопросами «социокультурного воспроизводства, распространения определенных культурных ценностей и норм» [2, с. 3].

По мнению немецкого социолога Ф. Келлера, образовательная система «ведет к репродукции культурных систем тем, что она обеспечивает знания и навыки, которые предполагаются для осуществления профессии и которые необходимы для участия в общественной жизни. Функция квалификации описывает таким образом задачи, которые образовательная система реализует по отношению к экономической системе» [3, S. 27]. Позиция этого ученого во многом справедлива, особенно в том, что репродукция социокультурных знаний и навыков является важнейшей функцией образовательной системы, обеспечивающей подготовку человека к участию в общественной жизни. Однако при этом недостаточным представляется видение современного социума как трехуровневой модели, включающей политическую, экономическую и образовательную структуры. По сути автор говорит о том, что назначение образования определяется его зависимостью от экономики, что буквально означает сохранение лишь таких профессиональных компетенций, которые демонстрируют экономический эффект. Нельзя не согласиться с тем, что образовательная система должна гарантировать высокий уровень воспроизводства и приращения знаний, значимых для общества в экономическом аспекте. Более того, данное требование видится обоснованным, поскольку образование выступает одним из главных факторов, способствующих экономическому благополучию населения. В рамках модернизации экономики, повышения ВВП, решения других стратегических вопросов государства оценка функционирования образовательной системы с точки зрения ее обусловленности экономическими фракторами вполне оправданна. Однако сводить социальные функции образования лишь к репродукции навыков, обеспечивающих экономический эффрект, детерминируемых взаимосвязями образовательной и экономической систем, неправомерно и даже опасно.

Проблема некоторого «упрощения» анализа системы высшего образования связана в целом с особенностями структурно-функционального подхода. Его применение позволяет рассматривать высшую школу в качестве подсистемы общества, которая взаимодействует с другими подсистемами как внутри образовательной системы, так за ее пределами. При этом структурнофункциональный анализ позволяет теоретически и методологически выделять отдельные функции высшего образования в качестве самостоятельных единиц. Как показывает изучение социологической литературы по данной проблематике, теория структурно-функционального анализа остается одной из немногих востребованных макротеорий высшего образования, обусловливающих важность и задающих направления соответствующих эмпирических исследований.

Однако, несмотря на распространенность и популярность, структурно-функциональный анализ нельзя считать бесспорным. Его недостатки при изучении системы высшего образования и ее функций проявляются в двух существенных моментах.

- Институциональная оценка высшей школы сопровождается квазимеханическим детерминированием индивидуального развития. Иными словами, индивидуальное действие, стремление постоянно предполагаются. При этом то обстоятельство, что субъекты образовательной системы имеют разные организационные возможности, остается в контексте структурно-фрункционального анализа едва заметным и не образует систематическую часть структурно-функционального понимания образовательной системы.

- Структурно-функциональный подход предполагает, что образовательная система (в данном случае высшей школы) рассматривается как подсистема общества, которая находится во 
взаимном функциональном обмене с его другими элементами. Теоретически и методологически разрабатываются в дальнейшем только функции образования как такового. По мнению немецкого социолога Т. Брюземейстера, образовательная система превращается в «посредника» для других подсистем социума [4, S. 45].

Автор популярной в Европе книги «Новая теория школы» Г. Фенд справедливо полагает, что причины критики структурно-функционального анализа кроются в том, что при описании образовательной системы используется концепция идеальных типов, в рамках которой она рассматривается как часть социальной системы, существующей в отрыве от процессов возникновения и изменения. Отказ от региональной и исторической перспективы в отношении образования ведет также к тому, что трансформации и инновации неизбежно пробивают теоретические границы исследования образовательной системы в контексте функциональной парадигмы [5, S. 119]. Как полагает ученый, решение проблемы недостаточной реализации функциональной парадигмы может состоять в том, что образовательная система детерминирует не сами поступки акторов, а вероятности этих поступков пространство возможностей, которое может быть индивидуально устроено [6, S. 181].

«Система высшего профессионального образования в своем функционировании, - пишет Г.М. Джамалудинов, - основывается на достижении двух основных целей: 1) профессиональная подготовка и включение специалистов в различные сферы жизнедеятельности общества; 2) освоение личностью определенного уровня культуры. Эти цели могут эффективно достигаться только в условиях их резонанса, обеспечиваемого социальным институтом образования, что и составляет его основную функцию» [7, с. 14]. Позиция автора в целом справедлива. Однако, по нашему убеждению, квалифрикационная функция высшей школы объединяет обе цели. Приобретение посредством обучения навыков, необходимых человеку для участия в общественной жизни, обусловлено репродукцией культурной системы. Технически требуемые знания выступают лишь компонентой высшего образования, но не исчерпывают его. Структурно-функциональный анализ (даже в его классической разработке Э. Дюркгейма) не ограничивается описательными и фактологическими приемами. Напротив, он является существенным методологическим инструментом социокультурного анализа.

Таким образом, одним из ключевых направлений социологического исследования высшего образования является структурно-функциональный подход. Его содержание и применение не ограничивается фрактологическим описанием социальных процессов в сфере образования, а предполагает «понимающий» (в смысле веберовской социологии) вектор изучения и социокультурной интерпретации социальных функций высшей школы. Именно репродукция культурной системы, в которой объединяются знания и умения, необходимые для обеспечения участия человека в общественной жизни, социокультурном взаимодействии и общении, образует одну из важнейших социальных функций образования вообще и высшего образования в частности.

Выполняя функцию репродукции культурной системы, высшая школа решает несколько задач.

- Передача следующему поколению определенной культурной традиции: от элементарных навыков общения (традиций, ритуалов) до высокопрофессиональных (включая профессиональный язык, технику и технологию). Репродукция позволяет молодежи посредством высшего образования стать важной частью национальной культуры.

- Обеспечение усвоения социальных ценностей и норм, в конечном счете формирующего совместную социокультурную (в том числе профессиональную) идентичность и конструирующего общество.

- Передача знаний и навыков (квалификаций), необходимых для достижения успеха в профессии и самостоятельной жизни в социуме.

\section{Ссылки:}

1. Fend H. Neue Theorie der Schule: Einführung in das Verstehen von Bildungssystemen. Wiesbaden, 2006. $204 \mathrm{~S}$.

2. Кобжицкая Н.3. Социализация как функция института образования в трансформирующемся российском обществе : дис. ... канд. социол. наук. Иркутск, 2006. 190 с.

3. Keller F. Strukturelle Faktoren des Bildungserfolgs: wie das Bildungssystem den Übertritt ins Berufsleben bestimmt. Wiesbaden, 2014. $398 \mathrm{~S}$

4. Brüsemeister T. Bildungssoziologie: Einführung in Perspektiven und Probleme. Wiesbaden, 2008. 222 S

5. Fend H. Op. cit.

6. Ibid. S. 181

7. Джамалудинов Г.М. Эволюция социальных функций высшего образования в изменяющемся российском обществе : дис. ... д-ра социол. наук. М., 2005. 308 с.

\section{References:}

Brüsemeister, T 2008, Bildungssoziologie: Einführung in Perspektiven und Probleme, Wiesbaden, 222 S., (in German). 
Dzhamaludinov, GM 2005, Evolution of social functions of higher education in a changing Russian society, D.Phil. thesis, Moscow, 308 p., (in Russian).

Fend, H 2006, Neue Theorie der Schule: Einführung in das Verstehen von Bildungssystemen, Wiesbaden, 204 S., (in German). Keller, F 2014, Strukturelle Faktoren des Bildungserfolgs: wie das Bildungssystem den Übertritt ins Berufsleben bestimmt, Wiesbaden, 398 S., (in German).

Kobzhitskaya, NZ 2006, Socialization as a function of the institution of education in a transforming Russian society, PhD thesis abstract, Irkutsk, 190 p., (in Russian). 